\title{
Pharmaciana
}

Vol. 8, No.1, May 2018, Page. 77-86

ISSN: 2088 4559; e-ISSN: 24770256

DOI: $10.12928 /$ pharmaciana.v8i1.7336

\section{Formulation and physical stability test of oleanolic acid cream and gel}

\author{
Kartini $^{* 1}$, Endang Wahyu Fitriani ${ }^{2}$, Laurances Tansridjata ${ }^{1}$ \\ ${ }^{1}$ Departement of Phamaceutical Biology, Faculty of Pharmacy, University of Surabaya \\ ${ }^{2}$ Departement Pharmaceutics, Faculty of Pharmacy, University of Surabaya \\ Jl. Raya Kalirungkut Surabaya 60293, Indonesia
}

Submitted: 18-09-2017

Reviewed: 19-10-2017

Accepted: 27-11-2018

\begin{abstract}
Plantago major has been empirically used for wound healing. One of its chemical compounds, oleanolic acid, exhibited wound healing activity on hyperglycemic rats. This study aimed to (1) formulate oleanolic acid into topical dosage forms, i.e., cream and gel and (2) evaluate the physical stability of the products. Oleanolic acid was formulated into the dosage forms using stearic acid, isopropyl palmitate, and cetyl alcohol as the cream base and carbomer as the gel base. The cream and gel were then evaluated with accelerated stability test $\left(40 \pm 2^{\circ} \mathrm{C} / 75 \pm 5 \% \mathrm{RH}\right)$ and stability test at room temperature $\left(27 \pm 2^{\circ} \mathrm{C} / 73 \pm 5 \% \mathrm{RH}\right)$ for six weeks. The physical stability was determined using the following parameters: the visual appearance, density, viscosity, and flow properties of cream and gel, as well as the emulsion type and particle size of the cream. Data analysis were performed using one sample $t$-test and paired $t$-test. The results showed that the oleanolic acid cream and gel were able to maintain their visual appearance, density, viscosity, and flow properties during the six-week storage. Also, the oleanolic acid cream was able to keep its particle size and emulsion type during the tests.
\end{abstract}

Keywords: formulation, stability test, cream, gel, oleanolic acid

\section{Corresponding author:}

Kartini

Departement of Phamaceutical Biology

Faculty of Pharmacy, University of Surabaya

Email: kartini@staff.ac.id 


\section{INTRODUCTION}

Oleanolic acid (Fig. 1) is a secondary metabolite from the group of triterpenoids contained in several plant species, such as Olea europaea, Plantago major (Chiang et al., 2003b; Kartini et al., 2014), Mentha piperita (Rais and Ali, 2010), and Ocimum basilicum. Oleanolic acid together with its isomer, ursolic acid, has exhibited various pharmacological activities, namely COX-2 and cholinesterase inhibitor (Kolak et al., 2011; Ringbom et al., 1998; Stenholm et al., 2013), immunomodulator (Chiang et al., 2003a), and cancer prevention and treatment (Chiang et al., 2003b; Kolak et al., 2011; Lee et al., 2005; Liu, 1995; Liu, 2005; Pollier and Goossens, 2012; Ringbom et al., 1998; Shanmugam et al., 2013; Stenholm et al., 2013). Previous studies have concluded that oleanolic acid exhibits cytotoxicity against SiHa and Hep G2, KB, MCF-7, MDA-MB-231, HeLaS3, and A549 cancer cell line, and inhibit the productions of TNF- $\alpha$, IL-1 $\beta$, IL-6, and IFN- $\gamma$ (Kartini et al., 2014; Kartini et al., 2017). Also, it has been empirically proven to have anti-inflammatory and wound healing activities (Kuonen et al., 2013).<smiles>CC1(C)C2CC[C@]3(C)C(CC=C4[C@@H]3CC[C@@]3(C(=O)O)CCC(C)(C)[C@]43C)[C@@]2(C)CC[C@H]1O</smiles>

Figure 1. The chemical structure of oleanolic acid

In wound treatment, oleanolic acid is formulated first into a dosage form. The appropriate dosage form for wound healing is topical, i.e., applied to the skin surface for both local and systemic purposes. The combination of active ingredients and bases gives a wide range of opportunity for topical application. Topical dosage forms come in several types, including ointment, paste, cream, and gel. Cream is an emulsion containing one or more active dissolved drug substances and has relatively fluid consistency, while gel is a good transparent vehicle because it liquefies on contact with skin and gives cooling sensation (Yanhendri, 2012).

Among the conditions that have to be met for a good dosage form is physically stable. Inability to maintain physical properties under storage conditions fails to comply with the acceptance criteria for dosage forms. Their stability can be evaluated with accelerated stability test and stability test at room temperature (Guideline, 2003). Based on this background, research aiming to formulate oleanolic acid into cream and gel dosage forms and to test their stability is necessary. In this research, accelerated stability test and stability test at room temperature were performed with the following parameters: organoleptic properties, density, viscosity, flow properties, emulsion type, and particle size.

\section{MATERIALS AND METHODS Materials}

The materials used in this research were pharmaceutical grade products, namely stearic acid, cetyl alcohol, isopropyl palmitate, Nipagin, Nipasol, Span 60, sorbitol, and Tween 60 (obtained from CV. Tristar Chemical, Surabaya). Additional materials were oleanolic acid (Sigma, St. Louis, MO, USA) and Aqua purificata. 


\section{The formulation of oleanolic acid creams and gels}

The concentration of oleanolic acid formulated into cream and gel was $0.00375 \%$. It referred to the ursolic acid content, i.e., the isomer of oleanolic acid that exhibits wound healing activities (Mukherjee et al., 2013). The oleanolic acid cream was prepared using the formula in Table 1. The water phase (Nipagin, Nipasol, sorbitol, BHA, and Tween 60) was heated in a water bath $\left(70^{\circ} \mathrm{C}\right)$ until properly mixed, while the oil phase (stearic acid, cetyl alcohol, isopropyl palmitate, BHT, and Span 60) was heated in a water bath until melted completely. Both phases were mixed in a hot mortar and then crushed until a homogeneous mass of cream was formed. The oleanolic acid was poured into a different mortar, added with the cream base a little at a time, and mixed until homogeneous. The cream was then stored in a primary container, i.e., plastic pot.

The oleanolic acid gel was prepared using the formula in Table II. Paraben and BHA were dissolved in hot water. Carbomer was added to it by dispersion, allowed to expand, and then stirred in high speed with a homogenizer. $\mathrm{NaOH}$ solution was then poured into the resultant gel base. Finally, the oleanolic acid was added to the base and stirred until homogeneous. The gel was then stored in a primary container, i.e., plastic pot.

Table I. The formula of oleanolic acid cream (Lachman et al., 1986)

\begin{tabular}{cc}
\hline Ingredients & Composition $(\%)$ \\
\hline Oleanolic acid & 0.00375 \\
Stearic acid & 14.0 \\
Cetyl alcohol & 1.0 \\
Isopropyl palmitate & 1.0 \\
Methylparaben & 0.1 \\
Propylparaben & 0.01 \\
BHA & 0.02 \\
BHT & 0.1 \\
Span 60 & 2.0 \\
Sorbitol & 3.0 \\
Tween 60 & 1.5 \\
Aqua purificata ad & 100 \\
\hline
\end{tabular}

Table II. The formula of oleanolic acid gel (Remington and Beringer, 2000)

\begin{tabular}{cc}
\hline Ingredients & Percentage (\%) \\
\hline Oleanolic Acid & 0.00375 \\
Carbomer & 4 \\
BHA & 0.02 \\
NaOH & 1.6 \\
Methylparaben & 0.3 \\
Aqua purificata ad & 100 \\
\hline
\end{tabular}

\section{The physical stability test of oleanolic acid cream and gel}

The physical stability of the oleanolic acid cream and gel was evaluated using accelerated stability test (climatic chamber, $40 \pm 2^{\circ} \mathrm{C} / 75 \pm 5 \% \mathrm{RH}$ ) and stability test at room temperature $\left(27 \pm 2^{\circ} \mathrm{C} / 73 \pm 5 \% \mathrm{RH}\right)$. It was determined according to the following observation parameters: organoleptic properties, emulsion type, particle size, viscosity, and flow properties. The dosage forms in the accelerated stability test were evaluated in weeks $0,2,4$, and 6 , while the ones in the stability test at room temperature were observed in weeks 0 and 6. 
In this research, the organoleptic indicators included smell, color, and shape. The emulsion type of the cream was identified by applying it to a microscope slide, dyeing it with methylene blue, and observing the change in the background of the dosage form on the slide. The particle size was identified by applying the cream to a microscope slide and conducting continuous observations on particle size until 500 data were obtained. The viscosity was measured using a Brookfield cone and plate viscometer (Engineering Laboratories INC, Stoughton MA, USA). The gel flow was measured at room temperature. One-gram sample was placed on the cone. The measurements were performed by increasing the shear rate from $0.5 / \mathrm{sec}$ to $100 / \mathrm{sec}$, and the viscosity was read at every rotation per minute (rpm). The density of the dosage forms was measured with beaker glass. Empty beaker glass that had been calibrated with a given volume was weighed using an analytical scale. The dosage forms were poured into the beaker glass up to the calibration mark and then scaled using an analytical balance. The densities $(\rho)$ of the dosages forms were calculated using the equation $\rho=\left(m_{1}-m_{2}\right) / v$, where $m_{1}$ : the mass of beaker glass filled with the dosage form, $m_{2}$ : the mass of empty beaker glass, and $\mathrm{v}$ : the volume of the dosage form.

\section{RESULTS AND DISCUSSION \\ Organoleptic properties}

The results of organoleptic observations showed that the cream was homogeneously white and had a distinctive smell (Figure 2a). Meanwhile, the gel was homogeneous and clear yellowish and had a specific scent (Figure 2b). The stability of the oleanolic acid cream and gel under different temperature was tested at high and room temperature for six weeks.
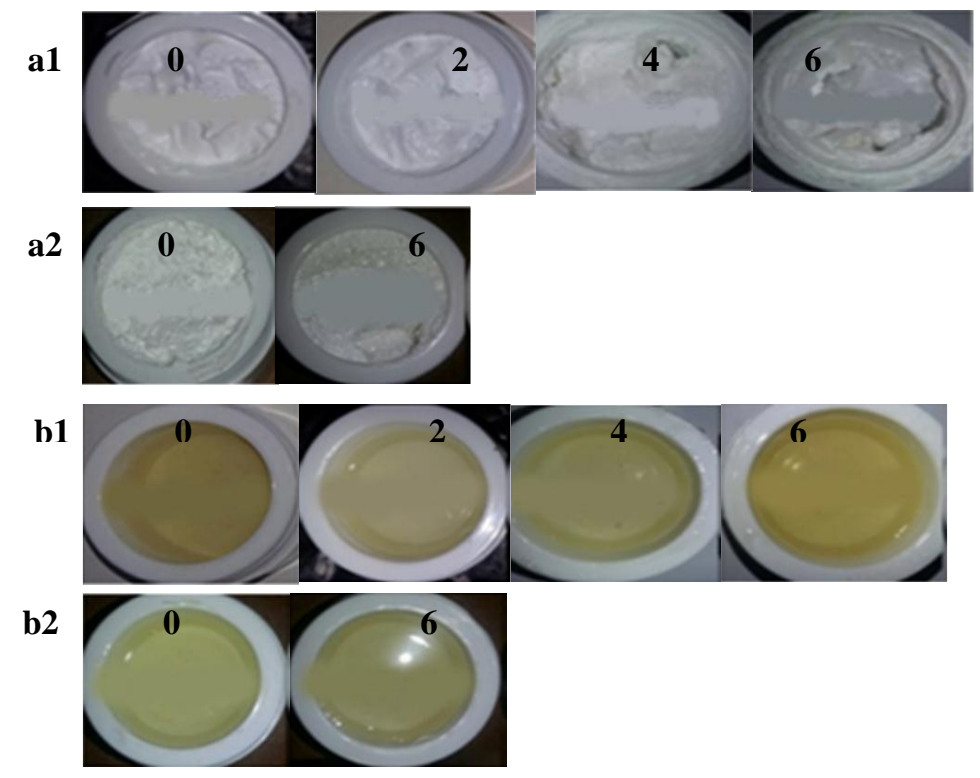

Figure 2. The results of organoleptic observations on oleanolic acid cream (a) and gel (b) stored in a climatic chamber (1) and at room temperature (2). The numbers in the figure $(0,2$, 4 , and 6) showed the duration of storage in weeks

The results showed that both dosage forms did not experience separation when stored at either elevated or room temperature. Different temperature treatments were necessary to see the ability of the dosage forms to maintain their properties during the time of storage. Cream is an emulsion system in which high temperature can increase the kinetic energy of droplets, constituting the dispersed phase, and induce the merging of globules and the swelling of globular diameter. On the contrary, cold 
temperature decreases the solubility of the emulsifier in the oil phase and the water phase that the effectiveness of emulsifier to coat the globules diminishes (Lachman et al., 1986).

\section{Densities}

The observation results of the densities of oleanolic acid cream and gel stored in a climatic chamber are presented in Table III. The storage duration (weeks) and the density of each replication were plotted into a graph. The slope of the graph was calculated and then examined with one sample $t$ test using zero test point. The statistical analysis of the oleanolic acid cream and gel, as well as their bases, resulted in $p>0.05$, indicating the absence of change in the densities of the dosage forms during the six-week storage.

Table III. The densities of the dosage forms stored at temperature $40 \pm 2^{\circ} \mathrm{C} / \mathrm{RH} 75 \pm 5 \%$

\begin{tabular}{ccccc}
\hline \multirow{2}{*}{ Weeks } & \multicolumn{4}{c}{ Densities $(\mathbf{g} / \mathbf{m l})$} \\
\cline { 2 - 5 } & Cream & Cream Base & Gel & Gel Base \\
\hline 0 & $1.07 \pm 0.07$ & $0.90 \pm 0.02$ & $1.20 \pm 0.02$ & $1.23 \pm 0.01$ \\
2 & $0.78 \pm 0.18$ & $0.89 \pm 0.05$ & $1.25 \pm 0.08$ & $1.08 \pm 0.09$ \\
4 & $0.84 \pm 0.05$ & $0.87 \pm 0.03$ & $1.77 \pm 0.05$ & $1.09 \pm 0.12$ \\
6 & $0.82 \pm 0.14$ & $0.82 \pm 0.12$ & $1.21 \pm 0.04$ & $1.03 \pm 0.11$ \\
\hline
\end{tabular}

The observation results of the densities of oleanolic acid cream and gel stored at room temperature are presented in Table IV. The data were analyzed with paired $t$-test using $\alpha=0.05$. This statistical analysis produced $p>0.05$, indicating the absence of change in the densities of the dosage forms during the six-week storage.

The absence of change in the densities of both oleanolic acid cream and gel shows that they remain homogeneous during the time of storage. This stability is a guarantee that the active substances are dispersed evenly throughout the dosage forms. In other words, the homogeneity is controlled correctly (Yoshioka and Stella, 2000).

Table IV. The densities of the dosage forms stored at room temperature $\left(27 \pm 2^{\circ} \mathrm{C} / 73 \pm 5 \%\right.$ RH)

\begin{tabular}{ccccc}
\hline \multirow{2}{*}{ Weeks } & \multicolumn{4}{c}{ Densities $(\mathbf{g} / \mathbf{m L})$} \\
\cline { 2 - 5 } & Cream & Cream Base & Gel & Gel Base \\
\hline 0 & $1.07 \pm 0.07$ & $0.90 \pm 0.02$ & $1.20 \pm 0.03$ & $1.23 \pm 0.01$ \\
6 & $1.09 \pm 0.02$ & $0.97 \pm 0.006$ & $1.19 \pm 0.06$ & $1.20 \pm 0.02$ \\
\hline
\end{tabular}

\section{Emulsion type and droplet size}

The observation results showed that the emulsion type of oleanolic acid cream was an oil-inwater emulsion (M/A, Figure 3) during the six-week storage both in a climatic chamber and at room temperature. It was evidenced by the blue (water) and not-blue (oil) colors on the background of the observation. Also, this emulsion type was in line with the expected specification, i.e., oil-in-water emulsion. 

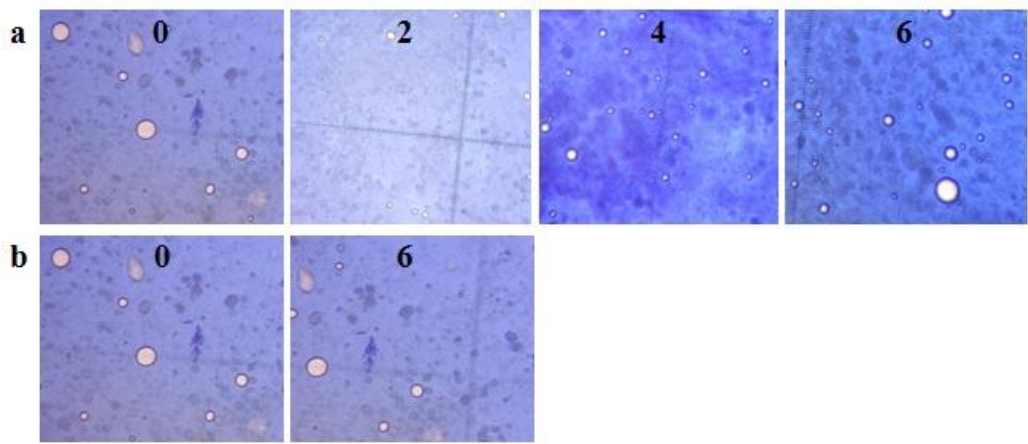

Figure 3. The observation results of the emulsions of oleanolic acid cream stored in a climatic chamber (a) and at room temperature (b). The numbers in the figure $(0,2,4$, and 6$)$ represent the storage duration in weeks

The observation results of the particle size of oleanolic acid cream stored in a climatic chamber are presented in Table V. The storage duration (weeks) and particle size of each replication were plotted on a graph. The slope of the graph was calculated and then examined with one sample $t$-test using zero test point. The statistical analysis of the cream and cream base resulted in $p>0.05$, indicating the significant difference of particle size during the six-week storage in a climatic chamber.

The observation results of the particle size of oleanolic acid cream stored at room temperature are presented in Table VI. Based on the observations, a statistical analysis, namely paired $t$-test with $\alpha$ $=0.05$, was performed. It showed a significance value of more than 0.05 , indicating the absence of significantly different particle size during the six-week storage at room temperature.

Table V. The particle size of oleanolic acid cream stored at temperature $40 \pm 2^{\circ} \mathrm{C} / 75 \pm 5 \% \mathrm{RH}$

\begin{tabular}{ccc}
\hline \multirow{2}{*}{ Weeks } & \multicolumn{2}{c}{ Particle Size $(\boldsymbol{\mu m})$} \\
\cline { 2 - 3 } & Cream & Cream Base \\
\hline 0 & $6.96 \pm 0.02$ & $6.97 \pm 0.09$ \\
2 & $6.85 \pm 0.10$ & $6.83 \pm 0.07$ \\
4 & $6.78 \pm 0.03$ & $6.81 \pm 0.03$ \\
6 & $6.82 \pm 0.10$ & $6.86 \pm 0.09$ \\
\hline
\end{tabular}

Table VI. The particle size of oleanolic acid cream stored at room temperature $\left(27 \pm 2^{\circ} \mathrm{C} / 73 \pm 5 \%\right.$ RH)

\begin{tabular}{ccc}
\hline Weeks & \multicolumn{2}{c}{ Particle Size $(\boldsymbol{\mu m})$} \\
\cline { 2 - 3 } & Cream & Cream Base \\
\hline 0 & $6.96 \pm 0.02$ & $6.97 \pm 0.09$ \\
6 & $6.93 \pm 0.10$ & $6.77 \pm 0.14$ \\
\hline
\end{tabular}

The particle diameter of the oleanolic acid cream formulated in this research was in line with previous studies, i.e., 0.5-10 $\mu \mathrm{m}$ (Martin et al., 1993). The droplet shape and size of an emulsion are influenced by the amount and efficiency of the emulsifier and the mixing and stirring processes. Observations on the cream showed that the droplet was present in the forms of not only balls but also 
other shapes. This form is believed to be caused by stirring during the formulation and the merging of two or more droplets spontaneously, resulting in irregular shapes.

\section{Viscosity and flow properties}

The observation results of the viscosity of oleanolic acid cream and gel stored in a climatic chamber and at room temperature are presented in Table VII and VIII, respectively. The storage duration (weeks) and viscosity of each replication were plotted on a graph. The slope of the graph was calculated and then examined with one sample $t$-test using zero test point. The analysis of oleanolic acid cream and gel, as well as their bases, produced $p>0.05$, indicating the absence of statistically different viscosities during the six-week storage.

Table VII. The viscosity of oleanolic acid cream and gel stored at temperature $40 \pm 2^{\circ} \mathrm{C} / 75 \pm 5 \%$ RH

\begin{tabular}{ccccc}
\hline \multirow{2}{*}{ Weeks } & \multicolumn{4}{c}{ Viscosity (cPs) } \\
\cline { 2 - 5 } & Cream & Cream Base & Gel & Gel Base \\
\hline 0 & $1591 \pm 354.31$ & $775 \pm 92.11$ & $4566 \pm 505.55$ & $920 \pm 54.50$ \\
2 & $2534 \pm 374.53$ & $794.67 \pm 75.86$ & $3919 \pm 299.44$ & $919 \pm 38.79$ \\
4 & $2501 \pm 722.71$ & $859 \pm 21.66$ & $3282 \pm 680.12$ & $905 \pm 49.80$ \\
6 & $1979 \pm 608.76$ & $885 \pm 23.25$ & $4293 \pm 659.85$ & $956 \pm 55.43$ \\
\hline
\end{tabular}

Table VIII. The viscosity of oleanolic acid cream and gel stored at room temperature $\left(27 \pm 2^{\circ} \mathrm{C} / 73 \pm 5 \% \mathrm{RH}\right)$

\begin{tabular}{ccccc}
\hline \multirow{2}{*}{ Weeks } & \multicolumn{4}{c}{ Viscosity (cPs) } \\
\cline { 2 - 5 } & Cream & Cream Base & Gel & Gel Base \\
\hline 0 & $1591 \pm 354.31$ & $775 \pm 92.11$ & $4566 \pm 505.55$ & $920 \pm 54.50$ \\
6 & $2240 \pm 442.27$ & $928 \pm 32.08$ & $6383.67 \pm 2065.12$ & $923.33 \pm 30.62$ \\
\hline
\end{tabular}

The viscosity of oleanolic acid gel and cream was the same as the expected specification, i.e., 1000-5000 cPs. It was also in line with previous research (Yuliani et al., 2012), which found that the viscosity of the gel of Anredera cordifolia (mignonette vine) using carbomer as the gelling agent was more stable than using Ca-alginate or CMC-Na. Carbomer can maintain the viscosity of a system through its capacity to keep the network formation. Therefore, a higher concentration can reduce the change (the difference) in the viscosities of the dosage forms.

The graphs of the observed flow properties are presented in Fig. 4. Based on the measurements of the viscosities of cream and gel at various rpm, the viscosity value decreases as the rpm (shearing stress) increases. As a conclusion, the flow properties of oleanolic acid cream and gel were pseudoplastic. This characteristic was due to the addition of pressure and shear rate, causing the molecules that were previously irregular to start to order themselves and form a straight line so that the flow resistance became smaller (Singh, 2006). 

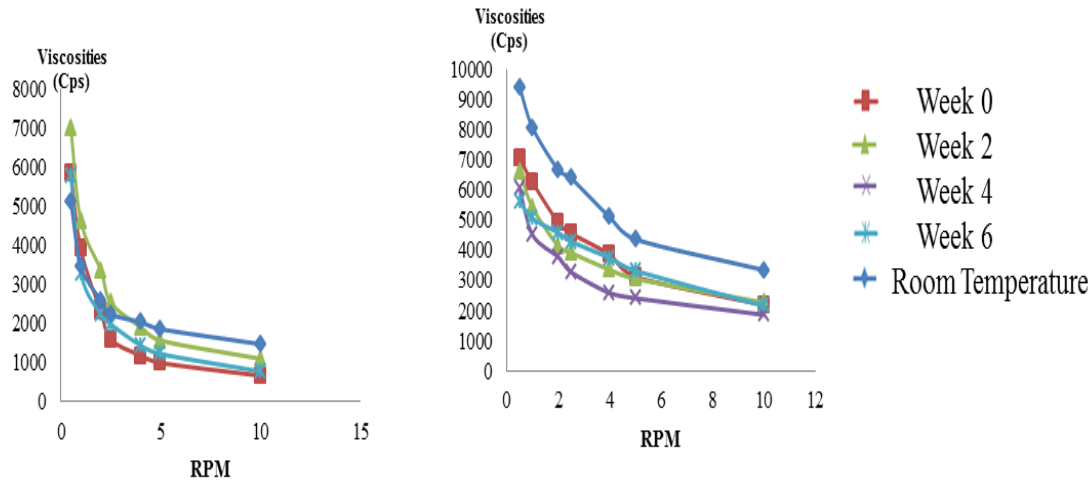

Figure 4. The profile of the flow properties of oleanolic acid cream (a) and gel (b) at temperatures $40 \pm 2^{\circ} \mathrm{C} / 75 \pm 5 \% \mathrm{RH}$ and $27 \pm 2^{\circ} \mathrm{C} / 73 \pm 5 \% \mathrm{RH}$

\section{CONCLUSION}

Based on this research,it can be concluded that the two dosage forms of oleanolic acid, namely cream and gel, did not experience any changes in their organoleptic properties, densities, viscosities, and flow properties during the six-week storage. Also, the oleanolic acid cream was able to maintain its particle size and emulsion type during the tests.

\section{ACKNOWLEDGMENT}

This research was supported by the Indonesian Ministry of Research, Technology, and Higher Education under the scheme of applied product research in 2017 [contract research number 120/SP2H/LT/DRPM/IV/2017].

\section{REFERENCES}

Chiang, L.C., Chiang, W., Chang, M.Y., Lin, C.C., 2003a. In vitro cytotoxic, antiviral and immunomodulatory effects of Plantago major and Plantago asiatica. Am J Chin Med, 31: 22534.

Chiang, L.C., Ng, L.T., Chiang, W., Chang, M.Y., Lin, C.C., 2003b. Immunomodulatory activities of flavonoids, monoterpenoids, triterpenoids, iridoid glycosides and phenolic compounds of Plantago species. Planta Med, 69: 600-4.

Guideline, I.H.T., 2003. Stability testing of new drug substances and products. Q1A (R2). current step 4.

Kartini, Piyaviriyakul, S., Siripong, P., Vallisuta, O., 2014. HPTLC simultaneous quantification of triterpene acids for quality control of Plantago major L. and evaluation of their cytotoxic and antioxidant activities. Industrial Crops and Products, 60: 239-46.

Kartini, Piyaviriyakul, S., Thongpraditchote, S., Siripong, P., Vallisuta, O., 2017. Effects of Plantago major extracts and its chemical compounds on proliferation of cancer cells and cytokines production of lipopolysaccharide-activated THP-1 macrophages. Pharmacognosy Magazine, 13: 393-9.

Kolak, U., Boğa, M., Uruşak, E.A., Ulubelen, A., 2011. Constituents of Plantago major subsp. intermedia with antioxidant and anticholinesterase capacities. Turkish Journal of Chemistry, 35: $637-45$.

Kuonen, R., Weissenstein, U., Urech, K., Kunz, M., Hostanska, K., Estko, M., Heusser, P., Baumgartner, S., 2013. Effects of lipophilic extract of viscum album L. And oleanolic acid on 
migratory activity of NIH/3T3 fibroblasts and on HaCat keratinocytes. Evidence-Based Complementary and Alternative Medicine, 2013:1-7.

Lachman, L., Lieberman, H.A., Kanig, J.L., 1986. The theory and practice of industrial pharmacy. Lea \& Febiger Philadelphia.

Lee, T.-H., Juang, S.-H., Hsu, F.-L., Wu, C.-Y., 2005. Triterpene Acids from the Leaves of Planchonella Duclitan (Blanco) Bakhuizan. Journal of the Chinese Chemical Society, 52: 127580.

Liu, J., 1995. Pharmacology of oleanolic acid and ursolic acid. J Ethnopharmacol, 49: 57-68.

Liu, J., 2005. Oleanolic acid and ursolic acid: Research perspectives. Journal of Ethnopharmacology $100,92-4$.

Martin, A.N., Swarbrick, J., Cammarata, A., 1993. Physical pharmacy: physical chemical principles in the pharmaceutical sciences. Lea \& Febiger Philadelphia.

Mukherjee, H., Ojha, D., Bharitkar, Y.P., Ghosh, S., Mondal, S., Kaity, S., Dutta, S., Samanta, A., Chatterjee, T.K., Chakrabarti, S., 2013. Evaluation of the wound healing activity of Shorea robusta, an Indian ethnomedicine, and its isolated constituent (s) in topical formulation. Journal of Ethnopharmacology, 149: 335-43.

Pollier, J., Goossens, A., 2012. Oleanolic acid. Phytochemistry, 77: 10-5.

Rais, I., Ali, M., 2010. Densitometric HPTLC method for analysis of oleanolic acid in Mentha piperita L. International Journal of Research in Ayurveda and Pharmacy, 1: 642-7.

Remington, J.P., Beringer, P., 2000. Remington: The science and practice of pharmacy. Lippincott Williams \& Wilkins.

Ringbom, T., Segura, L., Noreen, Y., Perera, P., Bohlin, L., 1998. Ursolic acid from Plantago major, a selective inhibitor of cyclooxygenase-2 catalyzed prostaglandin biosynthesis. J Nat Prod, 61: 1212-5.

Shanmugam, M.K., Dai, X., Kumar, A.P., Tan, B.K., Sethi, G., Bishayee, A., 2013. Ursolic acid in cancer prevention and treatment: molecular targets, pharmacokinetics and clinical studies. Biochem Pharmacol, 85: 1579-87.

Singh, Y., 2006. Martin's physical pharmacy and pharmaceutical sciences. Department of Pharmaceutics Ernest Mario School of Pharmacy Rutgers, The State University of New Jersey.

Stenholm, A., Goransson, U., Bohlin, L., 2013. Bioassay-guided supercritical fluid extraction of cyclooxygenase-2 inhibiting substances in Plantago major L. Phytochem Anal, 24: 176-83.

Yanhendri, S.W.Y., 2012. Berbagai bentuk sediaan topikal dalam dermatologi. Cermin Dunia Kedokteran 194 (36): 423-30.

Yoshioka, S., Stella, V.J., 2000. Stability of drugs and dosage forms. Springer.

Yuliani, S.H., Fudholi, A., Pramono, S., 2012. Physical properties of wound healing gel of ethanolic extract of binahong (Anredera cordifolia (Ten) Steenis) during storage. Indonesian J. Pharm, 23 (4): 203-8. 
